\title{
Serotonergic mediation of postprandial colonic tonic and phasic responses in humans
}

\author{
M R von der Ohe, R B Hanson, M Camilleri
}

\begin{abstract}
This study examined the hypothesis that $\mathbf{5 H T}_{3}$ mechanisms mediate the postprandial gastrocolonic response in humans. Fasting and postprandial colonic tone and motility were studied in 12 healthy volunteers and the effects of a selective $\mathbf{5 H T}_{3}$ antagonist, ondansetron assessed in a double blind, randomised, placebo controlled fashion. A manometry barostat assembly was positioned in the transverse or descending colon to quantitate contractile activity fasting, after drug infusion and postprandially after a 1000 kcal meal. Fasting colonic tone and motility indices were similar in the placebo and ondansetron groups; ondansetron did not affect fasting motility. The placebo group showed a significant reduction in barostat balloon volume (signifying increased tone) from $232 \mathrm{ml}$ (median, interquartile range (IQR) 179-261) during fasting to $181 \mathrm{ml}$ (median, IQR 128-208) (postprandially) $(p=0.02)$. In contrast, the ondansetron group did not have a tonic colonic response (median $248 \mathrm{ml}$ (IQR 199-300) fasting to median, $226 \mathrm{ml}$ (IQR 185-290) postprandially) after the meal. Phasic volume events measured by the barostat increased postprandially in both groups. Postprandial motor activity measured by manometry increased significantly in the placebo group, but not in the ondansetron group. In conclusion, a $5 \mathrm{HT}_{3}$ mechanism participates in the physiological contractile responses in the human transverse and descending colon after ingestion of a high energy meal.

(Gut 1994; 35: 536-541)
\end{abstract}

Since the turn of the century, there has been an indefatigable interest in the colonic response to the ingestion of a meal. In his radiological studies in cats, Cannon ${ }^{1}$ noted that passage of food through the ileocaecal valve stimulated colonic activity. Hurst wrote 'On comparing the appearance of the colon every hour through the day, I was stuck by the fact that it only changed materially after those hours in which a meal had been taken'. ${ }^{2}$ Subsequently, Misiewicz et $a l^{3}$ and Snape et $a l^{4}$ performed quantitative studies showing increased colonic pressure activity, particularly in distal rather than proximal colon, ${ }^{3}$ and increased colonic spike (myoelectric) activity. These studies led to an interest in the mechanisms mediating this response: cholinergic pathways, ${ }^{35}$ gastrin, ${ }^{4}$ cholecystokinin, ${ }^{6}$ and prostaglandin $\mathrm{E}_{1}{ }^{7}$ were implicated. These studies were based chiefly on concomitant plasma measurements of putative mediators and effects of pharmacological agents. Subsequent studies reported repeated postprandial gastro- colonic responses during prolonged manometric studies $^{8}$ and radioisotopic colonic transit studies," and a regional variation in the time course of the colonic contractile response was suggested. ${ }^{10}$

The availability of more specific pharmacological antagonists in recent years has led to further approaches to understand the mechanism of the gastrocolonic response. For example, loxiglumide, cholecystokinin A receptor antagonist, did not inhibit the gastrocolonic response in health or patients with irritable bowel syndrome," in whom an exaggerated response is often associated with postprandial gain and diarrhoea. ${ }^{12}$

By applying an electronic barostat to the colon, recent studies show that there is a prominent tonic component in the gastrocolonic response. ${ }^{13} 14$ In humans, postprandial colonic tone could be inhibited by atropine ${ }^{15}$ suggesting muscarinic cholinergic control. Serotonin exerts profound effects on proximal colonic function in humans ${ }^{16}$ and on ileocolonic transit in an experimental animal model. ${ }^{17}$ As myenteric cholinergic neurons have $5 \mathrm{HT}_{3}$ receptors, ${ }^{18}$ we wished to test the hypothesis that $5 \mathrm{HT}_{3}$ mechanisms may mediate the gastrocolonic response in humans.

Our aim was to study fasting and postprandial motility and tone with particular interest in the 'effect of a $5 \mathrm{HT}_{3}$ antagonist, ondansetron, which was given in a randomised, double blind, placebo controlled fashion.

\section{Methods}

SUBJECTS

Twelve healthy subjects (seven male, five female; age range: $22-45$ years, mean: 31 ) were recruited by public advertisement. Informed written consent was obtained from all participants before the study. The protocol had been approved by the Mayo Clinic Institutional Review Board.

\section{COLONIC INTUBATION}

On the evening before the study, subjects ingested an oral colonic lavage solution (composed of polyethylene glycol and electrolytes (OLS, Abbott Laboratories, Chicago, IL) until the faecal effluent was clear liquid, free of particulate matter. At 800 am the next day, colonoscopy to the caecum was performed by one investigator (MC) with the subjects consciously sedated under the minimum dose (2-4 $\mathrm{mg}$ ) of intravenous midazolam (Versed, Roche Laboratories, Nutley, $\mathrm{NJ}$ ) necessary to maintain acceptable comfort. No endoscopic abnormalities were seen and no solid matter was retained in 
the colon of any subject. A 4 metre, soft tipped, Teflon coated guide wire (Microvasive, Hobbs Medical Inc, Stafford Springs, CT) was inserted under fluoroscopic control into the caecum, and the colonoscope was withdrawn. A combined assembly consisting of four manometric catheters with a barostat balloon (described below) was then guided into the colon over the guide wire with the aid of fluoroscopy. In six subjects, the tube was inserted with the barostat balloon positioned in the transverse colon; in six subjects, the balloon was left in the proximal descending colon, just distal to the splenic flexure. Participants rested in a bed throughout the study; they recovered rapidly from the sedation and were alert at the start of experiments four hours after the tube was placed in the colon. At the end of the experiments, gentle traction on the catheter assembly with the balloon deflated permitted its removal without discomfort or complications.

\section{RECORDING ASSEMBLY}

The multilumen catheter comprised several lumens (Fig 1): one lumen of $4.8 \mathrm{~mm}$ in outer diameter and $3.2 \mathrm{~mm}$ in inner diameter served to operate the barostat balloon; a lumen for the guide wire; and four side hole capillary lumens (inner diameter; $0.78 \mathrm{~mm}$ each) for pneumo-

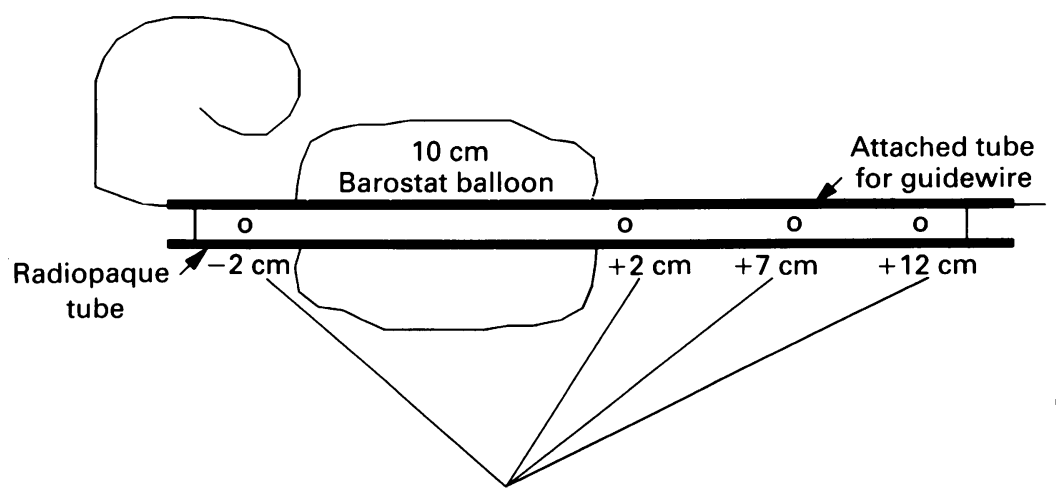

Manometric side holes

Figure 1: Multilumen catheter assembly showing $10 \mathrm{~cm}$ long barostat balloon, and manometric sideholes, $2 \mathrm{~cm}$ proximal and 2,7 , and $12 \mathrm{~cm}$ distal to it. Note guidewire passing through distal end of assembly.

\section{Baseline}

fasting volume Latency = time from meal ingestion to minimum volume
$=$ fasting tone

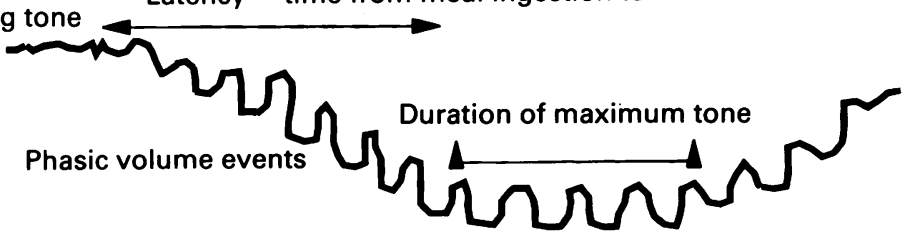

Minimum volume $=$ maximum tone

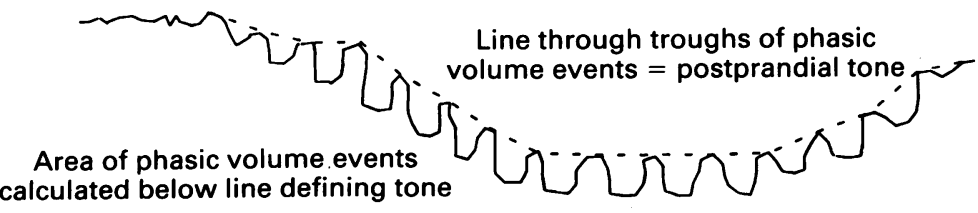
calculated below line defining tone

Figure 2: Scheme showing measurements performed on the barostat tracings with the aid of a computer analysis. hydraulic, low compliance perfusion manometry. The perfusion pressure was $69 \mathrm{kPa}$ and flow rates averaged $0 \cdot 1 \mathrm{ml} / \mathrm{min}$. The side holes were $2 \mathrm{~cm}$ proximal, and $2 \mathrm{~cm}, 7 \mathrm{~cm}$, and $12 \mathrm{~cm}$ distal to the barostat balloon. The barostat balloon was $10 \mathrm{~cm}$ long and was tied at both ends to metal rings incorporated in the catheter assembly. As reported previously, ${ }^{14}$ the polyethylene bags are infinitely compliant in the volume range 0 to $500 \mathrm{ml}$.

The intra-balloon pressure (operating pressure) was individually selected for each subject during the fasting period and was kept constant during the entire experimental period. The pressure that recorded the first signs of changes in intra-abdominal pressure induced by respiratory movements in each subject was identified, and was then clamped $2 \mathrm{~mm} \mathrm{Hg}$ above this minimal pressure. In this pressure clamped system, changes in the volume of the balloon reflect changes in wall tone of the viscus ${ }^{19}$ and increased intraluminal pressure.

\section{DATA STORAGE}

Pressures and volumes in the barostat balloon, phasic pressure fluctuations recorded by manometry, respiratory movements recorded by a pneumobelt, and experimental interventions were all recorded as analogue signals on Honeywell paper recorders. The analogue signals were sampled at $4 \mathrm{~Hz}$, digitised, entered into a computer (Microvax System; Digital Equipment Corporation, Boston, MA) and stored for later analysis on magnetic hard disk and paper. All analyses were performed by computer. The stored digitised data were scaled to match the experimental calibration and were then processed sequentially from the start of the recording.

\section{EXPERIMENTAL DESIGN (FIG 2)}

Four hours after placement of the colonic catheter assembly, all subjects were positioned on a bed in a $30^{\circ}$ head up, supine position. Fluctuations in balloon volumes, intra-balloon pressures, and intraluminal pressures were recorded during fasting for 60 minutes: 30 minutes before, and 30 minutes after intravenous infusion of ondansetron (Zofran, Glaxo Inc, Research Triangle, NC; dose: $0.15 \mathrm{mg} / \mathrm{kg}$, which is the route and highest single dose permitted in humans by the Food and Drug Administration of the United States) or saline as placebo. There were six volunteers in each group. The infusion period lasted five minutes. All participants then consumed a standardised $750 \mathrm{ml}, 1000 \mathrm{kcal}$ chocolate malt (53\% fat, 35\% carbohydrate, $12 \%$ protein). The meal, which has been used in previous studies 4691014 to induce the gastrocolonic response, was ingested within a period of five minutes. Balloon volume, intra-balloon pressure, and intraluminal manometric pressures were recorded for 120 minutes postprandially. Subjects were awake during the entire study period. 
filtering program (Digital Equipment Corporation, Boston, MA), barostat balloon volumes were cleared of respiratory artifacts (frequency $>10 / \mathrm{min}$ ) recorded simultaneously by the pneumobelt. Manometric data were cleared of movement artifact by computerised deletion of small pressure fluctuations $(<3 \mathrm{~mm} \mathrm{Hg}$ in magnitude, or $<4$ seconds in duration) that occurred simultaneously over all four manometric recording sites. The manometric data were then passed through a polynominal filter to remove minimal pressure variations (up to $6 \mathrm{~mm}$ $\mathrm{Hg}$ ) occurring with larger pressure waves.

Manometric activity - Phasic pressure activity quantitated in the manometric tracings, $2 \mathrm{~cm}$ proximal, and $2 \mathrm{~cm}$ and $7 \mathrm{~cm}$ distal to the barostat bag was averaged for the before and after drug fasting periods, and for the two hour postprandial periods. The computer program calculated the mean amplitude, area under the contractions, and frequency expressed/hour.

Barostat tracings - A modified VAX LAB program was used to separate baseline volume for phasic volume events recorded by the barostat balloon. Phasic volume events were defined as changes $\geqslant 10 \%$ comparative with the baseline volume, and occurring at a frequency of 1-4/ minute. This was the frequency of volume waves previously recorded in the human colon. ${ }^{14}$ is Baseline volumes were calculated by computer-

A Fasting

Postprandial

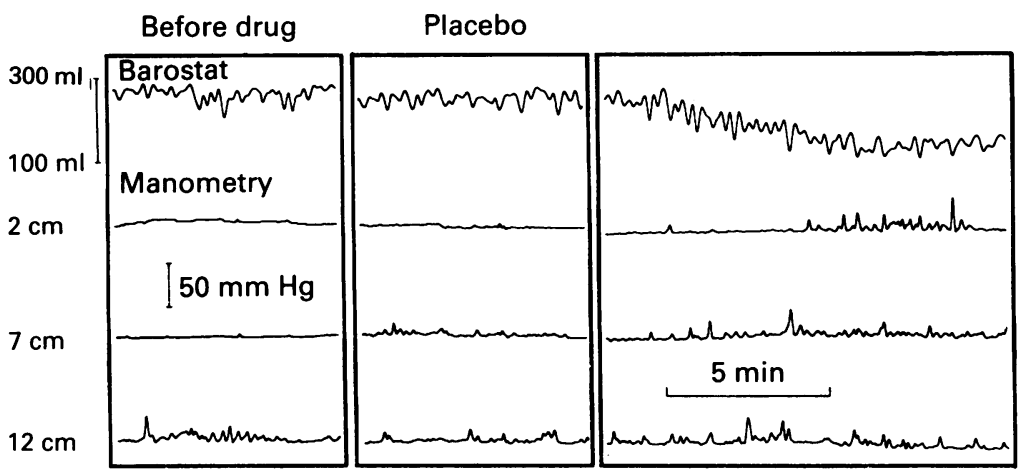

B

Fasting

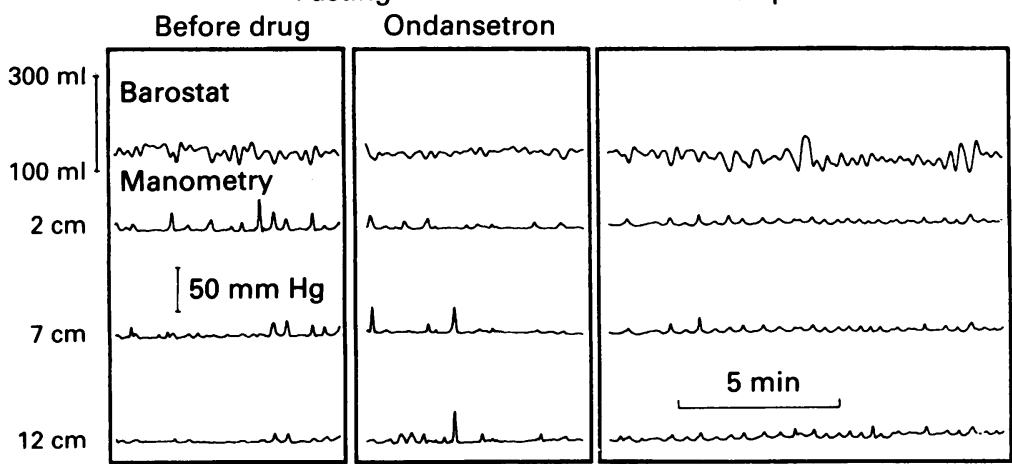

Figure 3: Original barostat/manometry tracings in two volunteers: $(A)=$ placebo and $(B)=$ ondansetron. Note placebo treatment is associated with postprandial reduction in baseline barostat volume; in contrast, ondansetron treatment inhibits postprandial change in baseline barostat volume. Note increased postprandial frequency of contractions detected on manometric recordings 2, 7, and $12 \mathrm{~cm}$ distal to the barostat balloon. ised exclusion of phasic volume events from the barostat tracings and were then averaged over each minute (minute baseline volumes). Mean of minute barostat volumes during the fasting (before and after drug) and postprandial periods were calculated. To correct for interindividual variations of fasting barostat volumes reflecting anatomical variations in colonic diameter, postprandial change in colonic tone was also expressed as a percentage of change from mean fasting barostat volumes. The maximum response of colonic tone to the meal was determined as the minimum postprandial volume that persisted for at least 10 consecutive minutes. The time from the start of the meal until the onset of this maximum response was calculated, and termed 'latency'. The duration of this maximum response was defined as the time (at least 10 minutes, according to the definition above) during which this response was not changed by more than $10 \%$. In summary, the following parameters were measured in the barostat tracings (Fig 2): fasting tone ( $\mathrm{ml}$ ), postprandial tone (ml), phasic volume events (number, mean amplitude, and area under the curve, all expressed/hour), and maximum tone (volume, latency, and duration).

\section{STATISTICAL ANALYSIS}

Two tailed unpaired $t$ test was used to compare fasting measurements and the percentage reduction in tone postprandially in the ondansetron and placebo groups $(\mathrm{p}<0.05$ being significant). Paired Student's $t$ test was used to compare baseline barostat volume (estimate of tone) during the fasting and postprandial periods, using both mean and minimum postprandial volumes. To compensate for two comparisons, we accepted $p<0.025$ as statistically significant. In analysing the phasic pressure or volume events, we restricted the statistical comparisons to the area under the curve (as calculated by the computer analysis) to avoid detecting differences by chance. Thus, comparison of fasting $v$ after drug ingestion, and fasting $v$ postprandial were performed separately for the placebo and ondansetron groups using paired $t$ test, and Bonferroni's correction was again applied ( $p<0.025$ being significant). All data are reported as median and interquartile range (IQR) because some of the data (for example, frequency and mean amplitude, but not area under the contractions) were not normally distributed.

\section{Results}

FASTING COLONIC TONE, BEFORE AND AFTER DRUG INGESTION

Representative examples of colonic barostat/ manometry tracings are given for two volunteers (Fig 3A: placebo; Fig 3B: ondansetron). There was no significant difference in the barostat operating pressures in the two groups (placebo median 14 , range $12-17 \mathrm{~mm} \mathrm{Hg}$; ondansetron median 15 , range $13-17 \mathrm{~mm} \mathrm{Hg}$ ). The fasting barostat volumes in the two groups before (placebo median $232 \mathrm{ml}$ (IQR 179-261), 


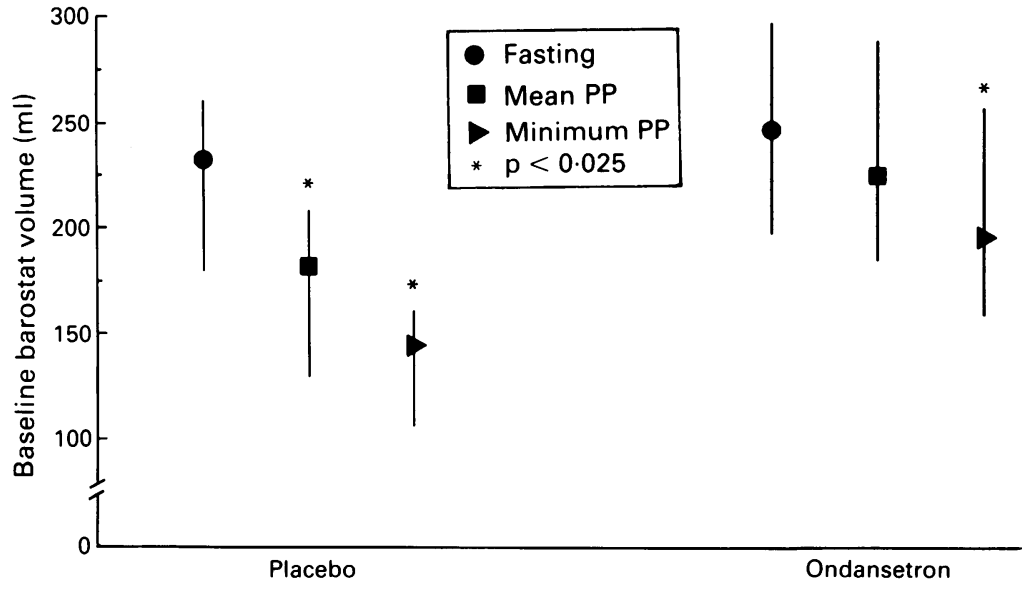

Figure 4: Effect of ondansetron and placebo on tone in the colon after a 1000 kcal meal $(P P=$ postprandial; data show both mean and minimum postprandial volume, indicating mean and maximum postprandial tone) ${ }_{\star}^{\star}: p<0.025 \mathrm{v}$ fasting in the placebo or ondansetron group. Note the appreciable reduction in barostat balloon volume with placebo (left panel), and the lack of effect of the meal on mean PP volume with ondansetron treatment (right panel). The minimum PP barostat volume with ondansetron treatment is also significantly different from fasting. ondansetron median $248 \mathrm{ml}$ (IQR 199-300)) and after (placebo median $230 \mathrm{ml}$ (IQR 164-262), ondansetron median $255 \mathrm{ml}$ (IQR 206-302)) administration of placebo or the drug were very similar.

\section{POSTPRANDIAL COLONIC TONE}

Ingestion of a meal resulted in an immediate significant reduction of minute barostat volumes in the placebo group. This reduction (median 25 (IQR 21-45)\% comparative with fasting) persisted throughout the two hour postprandial study period (Fig 3A, Fig 4). Ondansetron inhibited this overall postprandial increase in colonic tone (Fig 3B, Fig 4) with a reduction of volume of median 8 (IQR $3-16) \%(p \leqslant 0.01 v$ placebo). Ondansetron did not completely abolish the maximum increase in colonic tone to the meal, shown by the lowest volume of the barostat postprandially (Fig 4). The time between the ingestion of the meal and onset of this maximum response (latency) was not different in the placebo (median five minutes, IQR 0-33 minutes) and ondansetron (median eight minutes, IQR 4-12 minutes). Similarly the duration of these maximum responses was not different in the two groups (placebo median 20 minutes (IQR 15-50), ondansetron median 13 minutes (IQR 11-19)).

\section{COLONIC MANOMETRIC ACTIVITY AND PHASIC} VOLUME EVENTS (TABLE)

The fasting data in the ondansetron and placebo groups were not statistically different. Neither placebo nor ondansetron significantly affected phasic events during fasting. In the postprandial period, placebo treated subjects had a significant $(\mathrm{p}<0.025)$ increase in both manometric activity and phasic volume events. In the ondansetron group, postprandial phasic activity detected by manometry was not significantly different from fasting $(\mathrm{p}=0 \cdot 18)$. Postprandial phasic volume events were, however, increased comparative with fasting in this group $(\mathrm{p}=0.02)$.

\section{Discussion}

Our study clearly shows that tonic colonic responses after ingestion of a high fat meal are inhibited by the $5 \mathrm{HT}_{3}$ antagonist, ondansetron. Serotonin is known to stimulate proximal colonic function. ${ }^{16}$ Our results suggest that ondansetron inhibited a component of the gastrocolonic response. $^{3420}$ This inhibition of both tonic activity measured by the barostat and the phasic component of the gastrocolonic response measured by manometry is similar to that seen with atropine. ${ }^{15} \mathrm{We}$ are unaware of any data in published works that would suggest interaction between $5 \mathrm{HT}_{3}$ receptors and other putative mediators of the gastrocolonic response, such as gastrin, cholecystokinin, and prostaglandin $\mathrm{E}_{1}{ }^{467}$ Serotonin type 3 receptors have not been described on gastrointestinal smooth muscle, but are located in cholinergic interneurons. ${ }^{18}$ Our data suggest the hypothesis that the effects of ondansetron may be exerted through cholinergic neurons. Further studies are needed to evaluate whether ondansetron acts through cholinergic neurons or separately.

Colonic phasic volume events measured by the barostat were similar in the placebo and ondansetron groups. Thus, in contrast with the manometric data, the ondansetron group showed a significant increase in phasic volume events postprandially. This contrasts with the lack of any significant change in manometric phasic activity in the ondansetron group postprandially. One possible explanation for this apparent discrepancy is the comparative insensitivity of manometry in the colon when it has an internal diameter greater than $5.6 \mathrm{~cm} .{ }^{21}$ In a previous study, we noted that a change in luminal diameter from $5.2 \mathrm{~cm}$ to $5.8 \mathrm{~cm}$ resulted in a reduction of phasic events measured by manometry from 100 to $33 \%$ comparative with the number recorded by means of the barostat balloon. Because ondansetron inhibited the postprandial decrease in baseline volume seen with placebo, the colonic volume was greater with ondansetron, rendering manometry less sensitive to detect colonic wall motion, compared

Colonic motility by manometry and barostat. Median data (interquartile range in parentheses)

\begin{tabular}{|c|c|c|c|c|c|c|}
\hline & \multicolumn{3}{|l|}{ Placebo } & \multicolumn{3}{|l|}{ Ondansetron } \\
\hline & Fasting & After drug & Postprandial & Fasting & After. drug & Postprandial \\
\hline $\begin{array}{l}\text { Manometry } \\
\text { No peaks/hour } \\
\text { Mean amplitude }(\mathrm{mm} \mathrm{Hg}) \\
\text { Area under curve/hour } \times 10^{3}(\mathrm{~mm} \mathrm{Hg} / \mathrm{min}) \\
\text { Barostat }\end{array}$ & $\begin{array}{l}81(69-106) \\
11 \cdot 9(10 \cdot 2-13) \\
13(8 \cdot 8-14 \cdot 7)\end{array}$ & $\begin{array}{l}72(67-102) \\
12 \cdot 7(11 \cdot 7-13 \cdot 6) \\
12 \cdot 6(9 \cdot 1-14 \cdot 0)\end{array}$ & $\begin{array}{l}114(98-122) \\
14(12 \cdot 9-14 \cdot 3) \\
15 \cdot 5(13 \cdot 5-19 \cdot 8)^{\star}\end{array}$ & $\begin{array}{l}42(36-73) \\
11 \cdot 5(10 \cdot 0-14 \cdot 0) \\
7 \cdot 5(4 \cdot 5-8 \cdot 2)\end{array}$ & $\begin{array}{l}65(47-80) \\
12 \cdot 5(11 \cdot 4-15 \cdot 8) \\
9 \cdot 9(8 \cdot 2-11 \cdot 9)\end{array}$ & $\begin{array}{l}57(43-66) \\
11(10 \cdot 5-12 \cdot 5) \\
9 \cdot 4(8 \cdot 4-10 \cdot 6)\end{array}$ \\
\hline $\begin{array}{l}\text { No peaks/hour } \\
\text { Mean amplitude }(\mathrm{ml}) \\
\text { Area under curve/hour } \times 10^{3}(\mathrm{ml} / \mathrm{min})\end{array}$ & $\begin{array}{l}121(84-142) \\
38(35-46) \\
55 \cdot 2(37 \cdot 1-72 \cdot 7)\end{array}$ & $\begin{array}{l}109(90-134) \\
40(39-47) \\
57 \cdot 2(45 \cdot 3-75 \cdot 3)\end{array}$ & $\begin{array}{l}139(112-152) \\
48(43-52) \\
81.9(59 \cdot 9-89 \cdot 4)^{\star}\end{array}$ & $\begin{array}{l}104(63-134) \\
34(29-40) \\
37(19-58 \cdot 1)\end{array}$ & $\begin{array}{l}96(71-125) \\
37(33-58) \\
47 \cdot 6(34 \cdot 5-89 \cdot 2)\end{array}$ & $\begin{array}{l}114(84-144) \\
47(38-72) \\
71 \cdot 1(48 \cdot 1-96 \cdot 9)^{\star}\end{array}$ \\
\hline
\end{tabular}


with the inflated barostat balloon, which is apposed to the internal colonic surface. Hence, the amplitude or frequency of phasic events detected by manometry may not necessarily be accurate measures, and the barostat may record phasic contractile responses in the postprandial period with greater fidelity than manometry. Despite this discrepancy in the effects of ondansetron on phasic activity, the drug's inhibition of overall postprandial colonic tone is unequivocal. Data in this study show that a $5 \mathrm{HT}_{3}$ mechanism participates in mediating the physiological contractile response of the human transverse and descending colon to the ingestion of food. Two interpretations may be considered. Firstly, ondansetron may inhibit visceral afferents, ${ }^{22}$ preventing the stimulation of vagal cholinergic efferents participating in the gastrocolonic response. Alternatively, ondansetron may inhibit the enteric nerves in the final pathway of the gastrocolonic reflex, by inhibiting $5 \mathrm{HT}_{3}$ receptors on cholinergic $\mathrm{S}$ type interneurons. Ondansetron probably did not inhibit non-adrenergic, non-cholinergic AH type neurones, ${ }^{23}$ which are typically inhibitory, as this would have enhanced contraction of the colon, contrary with our findings in response to ondansetron. Ondansetron has very weak affinity for $5 \mathrm{HT} \mathrm{T}_{-1 \mathrm{c}}, \alpha_{1}$, and $\mu$ opioid receptors $\left(\mathrm{pk}_{\mathrm{b}} 5 \cdot 43-5 \cdot 49\right)$. As the selectivity ratio for $5 \mathrm{HT}_{3}$ receptors is about 100 -fold greater, however, we believe it is probable that the effects we saw are indeed mediated through $5 \mathrm{HT}_{3}$ receptors. ${ }^{24}{ }^{25} \mathrm{In}$ a separate study using a scintigraphic method to estimate ascending colon volume, we have recently shown that ondansetron also inhibits the reduction of ascending colon volume seen 30 120 minutes after ingestion of a $1000 \mathrm{kcal}$ meal. ${ }^{26}$ These complementary data confirm an important role for $5 \mathrm{HT}_{3}$ mechanisms in the physiological control of colonic motor function.

Ondansetron has previously been shown to inhibit colonic transit in health. ${ }^{27} 28$ The methods used in these studies were not sufficiently sensitive to discover if this was a result of a change in fasting or postprandial colonic transit. As meal induced colonic contractility is one of the main components resulting in mass movements or aboral transit, ${ }^{1-3}$ however, we hypothesise that ondansetron's effects are predominantly seen postprandially.

Antagonists to $5 \mathrm{HT}_{3}$ receptors have been used clinically as anti-emetics, particularly in patients with cisplatinum induced emesis. ${ }^{22}$ They may also have useful motor effects, however, in view of the location of $5 \mathrm{HT}_{3}$ receptors on cholinergic ${ }^{18}$ and non-adrenergic, non-cholinergic ${ }^{23}$ interneurons. Their main potential role in the colon may be in inhibiting motor dysfunctions associated with excessive contractility. The most common example of increased colonic phasic pressure activity met in clinical practice is irritable bowel syndrome ${ }^{3512}$; a less common example of rapid colonic transit associated with colonic hypertonicity but normal phasic pressure activity is carcinoid diarrhoea. ${ }^{29}$ These disorders may potentially be ameliorated with specific $5 \mathrm{HT}_{3}$ receptor antagonists. In fact, Steadman et al reported a moderate, though statistically insignificant, effect of ondansetron on colonic transit in irritable bowel syndrome patients selected on the basis of a predominant symptom of diarrhoea. ${ }^{30}$ In the future, it is conceivable that more potent $5 \mathrm{HT}_{3}$ antagonists may provide more effective means to inhibit the prominent colonic motor responses to ingestion of a meal, and possibly the postprandial diarrhoea associated with meal evoked colonic propulsion.

In summary, our studies show that $5 \mathrm{HT}_{3}$ mechanisms participate in mediating the gastrocolonic response. Although the site of action of the $5 \mathrm{HT}_{3}$ antagonist cannot be ascertained by out studies, our data suggest that the effect of $5 \mathrm{HT}_{3}$ antagonists should be tested in patients with irritable bowel syndrome or other disorders associated with exaggerated colonic motility.

This study was supported in part by General Clinical Research Center grant RR00585 from the National Institutes of Health. Dr Camilleri is a recipient of an American Gastroenterological Association/Smith Kline Beecham Clinical Research Award and of a grant from Glaxo, Inc. Doctor von der Ohe is funded by grant a grant from Glaxo, Inc. Doctor von der Ohe is funded by grant
Oh54/1-2 from Deutsche Forschungsgemeinschaft. We wish to Oh54/1-2 from Deutsche Forschungsgemeinschaft. We wish to
thank the nursing staff of the Mayo General Clinical Research thank the nursing staff of the Mayo General Clinical Research
Center and endoscopy assistants, C A Miller and J A Wiste, for Center and endoscopy assistants, C A Miller and J A Wiste, for
excellent technical support. We also thank Cindy Stanislav for typing and preparing this manuscript.

1 Cannon WB. The movements of the intestines studied by means of the Röntgen rays. Am F Physiol 1902; 6: 251-77.

2 Hurst AF. Sins and sorrows of the colon. In: Hunt T, ed. Selected writings of Sir Arthur Hurst 1879-1944. London: BMA Publishers, 1969: 92-9.

3 Misiewicz JJ, Connell AM, Pontes FA. Comparison of the effect of meals and prostigmine on the proximal and distal colon in patients with and without diarrhoea. Gut 1966; 7: colon in

4 Snape WJ Jr, Matarazzo SA, Cohen S. Effect of eating and gastrointestinal hormones on human colonic myoelectrical and motor activity. Gastroenterology 1978; 75: 373-8.

5 Sullivan MA, Cohen S, Snape WJ Jr. Colonic myoelectrica activity in irritable bowel syndrome. $N$ Engl $\mathcal{F}$ Med 1978; 298: 878-83.

6 Renny A, Snape WJ Jr, Sun EA, London R, Cohen S. Role of cholecystokinin in the gastrocolonic response to a fat meal. Gastroenterology 1983; 85: 17-21.

7 Delvaux M, Staumont G, Fioramonti J, Bueno L, Frexinos J. Alterations of colonic motility after oral administration of prostaglandin $\mathrm{E}_{1}$ analogue misoprostol in man. Fournal of prostaglandin $\mathrm{E}_{1}$ analogue misoprosto

8 Narducci F, Bassotti G, Gaburri M, Morelli A. Twenty four hour manometric recording of colonic motor activity in healthy man. Gut 1987; 28: 17-25.

9 Picon L, Lemann M, Flourié B, Rambaud J-C, Rain J-D, Jian $R$. Right and left colonic transit after eating assessed by a dual isotopic technique in healthy humans. Gastroenterology 1992; 103: 80-5.

10 Bassotti G, Betti C, Imbimbo BP, Pelli MA, Morelli A Colonic motor response to eating: a manometric investiga-
tion in proximal and distal portions of the viscus in man. Am f Gastroenterol 1989; 84: 118-22.

11 Niederau C, Faber S, Karaus M. Cholecystokinin's role in regulation of colonic motility in health and in irritable bowel syndrome. Gastroenterology 1992; 102: 1899-905.

12 Chaudhary NA, Truelove SC. Human colonic motility: a comparative study of normal subjects, patients with ulcerative colitis, and patients with the irritable colon syndrome. I. tive colitis, and patients with the irritable colon syndrome.

Resting patterns of motility. Gastroenterology 1961; 40: 1-17.
13 Neri M, Phillips SF, Fich A. Measurement of tone in canine colon. Am F Physiol 1991; 260: G505-11.

14 Steadman CJ, Phillips SF, Camilleri M, Haddad A, Hanson R. Variation of muscle tone in the human colon. Gastroenterology 1991; 101: 373-81.

15 Steadman CJ, Phillips SF, Camilleri M, Talley NJ, Haddad A, Hanson $R$. Control of muscle tone in the human colon. Gut 1992; 33: 541-6.

16 Fink S, Freedman G. The differential effect of drugs on the proximal and distal colon. Am $\mathcal{F}$ Med 1960; 28: $534-40$.

17 Oosterbosch L, von der Ohe M, Valdovinos MA, Kost LJ, Phillips SF, Camilleri M. Effects of serotonin on rat ileocolonic transit and fluid transfer in vivo: possible mechanisms of action. Gut 1993; 34: 794-8.

18 Boeckxstaens GE, Pelckmans PA, Rampart M, Bogers JJ, Verbeuren TJ, Herman AG, et al. Pharmacological Verbeuren TJ, Herman AG, et al. Pharmacological
characterization of 5-hydroxytryptamine receptors in the characterization of 5-hydroxytryptamine receptors in the
canine terminal ileum and ileocolonic junction. $\mathcal{F}$ Pharmacol Exp Ther 1990; 254: 652-8.

19 Azpiroz F, Malagelada J-R. Physiological variations in canine gastric tone measured by an electronic barostat. Am $\mathcal{F}$ Physiol 1985; 248: G229-37.

20 Dapoigny $M$, Cowles VE, Zhu Y-R, Condon RE. Vagal influence on colonic motor activity in conscious nonhuman primates. Am F Physiol 1992; 262: G231-6.

21 von der Ohe $M$, Hanson $R B$, Camilleri $M$. Barostat recording of intracolonic pressure activity: comparison with manometry in healthy human subjects. Gastroenterology 1992; 103: A1377. 
22 Cubeddu LX, Hoffman IS, Fuenmayor NT, Finn AL. Efficacy of ondansetron (GR 38032F) and the role of serotonin in cisplantin-induced nausea and vomiting. NEnglf Med 1990; 322: 810-6.

23 Tonini M, Rizzi CA, Manzo L, Onori L. Novel enteric 5HT receptors and gastrointestinal prokinetic action. Pharmaco Res 1991; 24: 5-14.

24 Dumuis A, Sebben M, Bockaert J. The gastrointestinal prokinetic benzamide derivatives are agonists at the nonprokinetic benzamide derivatives are agonists at the nonclassical 5-HT receptor (5-HT Pharmacol 1989; 340: 403-10.

25 Van Winigaarden I, Tulp MThM, Soudijn W. The concept of selectivity in 5-HT receptor research. Eur F Pharmacol 1990 188: $301-12$.

26 Scolapio JS, von der Ohe $M$, Hanson RB, Camilleri $M$. Postprandial function of human ascending colon: a biphasic response involving $5 \mathrm{HT}_{3}$ mechanism. Gastroenterology 1993; 104: A579.

27 Talley NJ, Phillips SF, Haddad A, Miller LJ, Zinsmeister AR. GR $38032 \mathrm{~F}$ (ondansetron), a selective $5 \mathrm{HT}_{3}$ antagonist, GR38032F (ondansetron), a selective $\mathrm{SHT}_{3}$ antagonist,
slows colonic transit in healthy man. Dig Dis Sci 1990; 35: slows colo

28 Gore S, Gilmore IT, Haigh CG, Brownless SM, Stockdale H, Morris AI. Colonic transit in man is slowed by ondansetron (GR38032F), a selective 5-hydroxytryptamine receptor (GR38032F), a selective 5-hydroxytryptamine receptor

9 von der Ohe MR Camilleri M, Kvols LK, Thomforde GM. on der Ohe MR, Camilleri M, Kvols LK, Thomforde GM. Small bowel and colonic motor dysfunction in patients with 329: 1073-8.

30 Steadman CJ, Talley NJ, Phillips SF, Zinsmeister AR. Selective $5-\mathrm{HT}_{3}$ receptor antagonist, Ondansetron, as treatment for diarrhea-predominant IBS. A pilot study. Mayo Clin Proc 1992; 67: 732-8. 